\title{
BMJ Open Economic impact of ulipristal acetate on surgical procedures for uterine fibroids in France
}

To cite: Fernandez $\mathrm{H}$, Jourdain 0 , Villefranque $V$, et al. Economic impact of ulipristal acetate on surgical procedures for uterine fibroids in France. BMJ Open 2017;7:e015571. doi:10.1136/ bmjopen-2016-015571

- Prepublication history for this paper is available online. To view these files, please visit the journal online (http://dx.doi. org/10.1136/bmjopen-2016015571).

Received 16 December 2016 Revised 17 March 2017 Accepted 5 May 2017

\section{CrossMark}

${ }^{1}$ Gynecology obstetric, AP-HP, Hôpital Bicêtre, Service de Gynécologie Obstétrique, 78 rue du Général Leclerc, Le Kremlin Bicêtre, France

${ }^{2}$ Université Paris-Saclay, 63 rue Gabriel Péri, Le Kremlin Bicêtre, France

${ }^{3}$ INSERM U1018 CESP,

Reproduction et développement de l'enfant, 82 rue du Général

Leclerc, Le Kremlin Bicêtre,

France

${ }^{4}$ Clinique Jean Villar, BordeauxBruges, France

${ }^{5}$ Maternité, Hôpital Simone Veil, 14 rue de Saint Prix, Eaubonne, France

${ }^{6}$ PregLem SA, Geneva,

Switzerland

${ }^{7}$ Cemka-Eval,boulevard Maréchal-Joffre, Bourg-laReine, France

Correspondence to Professor Hervé Fernandez; herve.fernandez@aphp.fr

\author{
Hervé Fernandez, ${ }^{1,2,3}$ Olivier Jourdain, ${ }^{4}$ Vincent Villefranque ${ }^{5}$ Matthieu Lehmann, ${ }^{6}$ \\ Antoine Lafuma, ${ }^{7}$ Matthieu Trancart $^{7}$
}

\section{ABSTRACT}

Objective To assess the budget impact of using ulipristal acetate (UPA) $5 \mathrm{mg}$ to treat women with uterine fibroids (UF) causing moderate to severe symptoms.

Design We modelled trends in the number of surgical procedures for symptomatic UF, with and without the use of UPA for preoperative or intermittent treatment and assessed the budget impact of UPA use from the French national healthcare insurance system perspective.

Setting A French national hospital database (PMSI) that records admissions and relative procedures to public and private hospitals.

Participants Women eligible for surgical procedures for uterine fibroids.

Main outcome measures Economic impact of UPA treatment.

Results This study based on observational retrospective data shows that the current use of UPA in its preoperative indication was associated with 5645 fewer surgeries from 2013 to 2015. Extrapolation suggests 17885 fewer surgeries from 2016 to 2019. Overall, preoperative use of UPA results in substantial cost savings for the French national healthcare insurance system, with a cumulated budget impact estimated at $€-5$ million from 2013 to 2015 and $€-13.5$ million from 2016 to 2019. In addition, treating women nearing the menopause ( $\geq 48$ years old) with intermittent treatment from 2017 to 2019 could produce an incremental cost saving of $€ 19$ million. Conclusions This study shows that the use of UPA in women eligible for surgical procedures for UF is associated with considerable savings for the French national healthcare insurance system in both preoperative and intermittent indications by decreasing the need to perform surgeries.

\section{INTRODUCTION}

Uterine fibroids (UF), also known as leiomyomas or myomas, are frequent benign smooth muscle tumours of the uterus. They are estimated to affect $20 \%-40 \%$ of women during reproductive years, with large variations from one population to another. ${ }^{1}$ Most women with UF have no symptoms, but UF can cause abnormal and excessive uterine bleeding, infertility, pelvic pain, dysmenorrhoea and/ or anaemia, thereby undermining quality

\section{Strengths and limitations of this study}

- Analysis based on exhaustive real-world data available in French national databases.

- Consistent and robust conclusions of the analysis (ulipristal acetate (UPA) is cost-saving), even during sensitivity analysis and considering the worst-case scenario.

- Conservative approach by excluding indirect costs associated with sick leave (which are partially compensated by the French national healthcare system) and by limiting the market penetration of UPA as a presurgical treatment.

- Inflexion point in the number of surgeries seen at the time of launch of UPA, solely attributed to the efficacy of UPA.

- Exploratory scenario for intermittent indication due to the limited availability of real-world data related to the use of intermittent UPA in routine practice.

of life. ${ }^{2}$ The prevalence of UF in France was estimated at $4.6 \%$ in a 2009 European survey ${ }^{3}$ (self-reported diagnosed UF in women aged between 15 and 49 years) and $8.8 \%$ in a 2014 French survey ${ }^{4}$ (diagnosed symptomatic UF in women aged between 30 and 55 years).

Despite the associated risks, hysterectomy is necessary for some patients with UF, whereas a more conservative approach can be considered for other women, depending on factors such as age, the wish for future pregnancy, characteristics of the fibroids, symptom severity and patient preferences. ${ }^{5}$ Recently, selective progesterone receptor modulators (SPRM) have been developed as therapeutic options for treatment of moderate to severe symptoms of UF. One SPRM, ulipristal acetate (UPA) $5 \mathrm{mg}$ (ESMYA), has been shown to significantly reduce uterine bleeding and myoma volume. ${ }^{67}$ The 'PEARL series' of clinical studies demonstrated the efficacy and safety of oral UPA in women with symptomatic UF . 891011

Based on the results of PEARL I and $\mathrm{II}^{78}$ UPA was first approved in February 2012 by 
the European Medicines Agency (EMA) for preoperative treatment of moderate to severe symptoms of UF in adult women of reproductive age with a treatment duration limited to 3 months. ${ }^{12}$ Reimbursement status was granted by the French Ministry of Health and Welfare in 2013 for one 3-month treatment course ${ }^{13}{ }_{-}{ }^{2}$, and UPA started to be marketed for this preoperative indication in August 2013.

In the PEARL II study, about half of the patients treated with either UPA or leuprolide acetate did not undergo surgery at the end of their medical treatment. Exploratory analysis of these patients showed that their fibroids began to regrow about 1 month after the last dose of leuprolide acetate, whereas the fibroid volume reduction was maintained at least up to 6 months after the end of treatment in most patients who received UPA. ${ }^{15}$

Recently, the PEARL IV study compared 5 and $10 \mathrm{mg}$ doses of UPA administered as repeated intermittent treatment (up to four 3-month courses, with breaks of 2 months, for a total study duration of 21 months). Uterine bleeding was controlled in, respectively, $73.3 \%$ and $75.0 \%$ of patients in the two groups at the end of the fourth course. After four courses, myoma volume fell by $67.0 \%$ in the $5 \mathrm{mg}$ group and by $70.4 \%$ in the $10 \mathrm{mg}$ group, a non-statistically significant difference. Efficacy was maintained during the off-treatment periods. ${ }^{10}$

Consequently, in April 2015, EMA extended the indications for UPA to cover repeated intermittent treatment courses of 3 months each in adult women of reproductive age with moderate to severe symptoms from UF. ${ }^{16}$ However, this indication is not yet reimbursed by the French national healthcare insurance system.

Although clinical data suggest a positive impact of UPA on the need for surgery among women with symptomatic UF, its economic impact has not been documented. The objective of this study was to assess the budget impact of UPA at the level of the French population, from the point of view of the national healthcare insurance system.

\section{METHODS}

The budget impact of UPA was estimated by using a dedicated model constructed in Microsoft Excel, in accordance with the Principles of Good Practice for budget impact analysis issued by the International Society for Pharmacoeconomics and Outcomes Research. ${ }^{17}$ On the basis of real-world data, we assessed the budget impact of UPA in women with moderate to severe UF who were eligible for surgical procedures. This study population corresponds to the conditions of UPA reimbursement by the French national healthcare insurance system for the preoperative indication, and to the most severe cases of intermittent indication granted by EMA.

Even though UPA shows substantial benefits in the segment of the intermittent indication not directly concerned by immediate surgical procedures, this population was not included in the analysis. Indeed, given the lack of real-world data for this population, theoretical analysis of the benefits associated with intermittent treatment would have been poorly informative. The study population represented about $10 \%$ of the estimated total population of women with moderate to severe UF in France (307000 patients, including women having surgical procedures).

The economic benefits associated with the use of UPA in the study population were measured in terms of the impact of UPA on the use of surgery, and compared with treatment costs in order to estimate the budget impact.

A counterfactual scenario was used to assess the hypothetical use of surgery in France if UPA had not been available from August 2013. The following two scenarios were then compared with this counterfactual scenario:

1. The current scenario, based on the use of surgery with UPA available in its current marketing situation in France (ie, the preoperative indication since August 2013);

2. An exploratory scenario modelling the potential incremental impact associated with the reimbursement of intermittent UPA after January 2017 concerning surgical treatment.

In this analysis, the benefits of intermittent indication were limited to the possibility of postponement of the surgery after the occurrence of menopause and, consequently, of avoidance of surgery. As the PEARL IV study ${ }^{10}$ evaluated the efficacy of intermittent treatment over a 2-year duration of exposure, the impact of intermittent UPA was only assessed in women nearing the menopause ( $\geq 48$ years old).

In all three scenarios, outcomes were estimated from exhaustive real-world data available in French national databases. The perspective was that of the French national healthcare insurance system (Caisse Nationale d'Assurance Maladie; CNAM). Healthcare costs associated with reimbursed UPA treatment units (standard packs of 28 pills) and surgical procedures were considered. A time horizon of 7 years was chosen (2013-2019) in order to assess the impact of both UPA indications on the surgical management of UF, from the market introduction of preoperative treatment to the end of a 3-year period of intermittent treatment availability.

\section{Identification of surgical procedures in national databases}

The number of surgical procedures for UF was estimated from the database of the French Medical Information System (Programme de Médicalisation des Systèmes d'Information; PMSI), which covers all French public and private hospitals. All hospital stays in a given year are available in standardised discharge reports and are collected in the PMSI database. This database is primarily used for invoicing purposes through a diagnosis-related group (DRG) system by hospitals to CNAM, but it can also be used to assess the number of patients treated per year for a specific disease and the number of hospital stays per patient. This database is used for epidemiological purposes by several public health organisations, such as the National Cancer Institute (Institut National du Cancer). 
Table 1 CCAM codes used to identify surgical procedures within the PMSI (a French national hospital database)

\begin{tabular}{llll}
\hline Access route & Hysterectomy & Myomectomy & Embolisation \\
\hline Vaginal & JKFA005; JKFA026 & \\
Laparoscopy & $\begin{array}{l}\text { JKFA006; JKFA018 } \\
\text { JKFC002; JKFC005 } \\
\text { JKFC006 }\end{array}$ & JKFC001; JKFC004 \\
Laparotomy & $\begin{array}{l}\text { JKFA015; JKFA024 } \\
\text { JKFA028; JKFA032 }\end{array}$ & JKFA016; JKFA022 & EDSF004; EDSF014 \\
\hline Hysteroscopy & & JKFE002 & \\
\hline Intra-arterial & & &
\end{tabular}

Hospital stays for UF were extracted from the PMSI database by using the ICD-10 codes for UF, namely D25 (leiomyoma of uterus); D25.0 (submucous leiomyoma of uterus); D25.1 (intramural leiomyoma of uterus); D25.2 (subserosal leiomyoma of uterus) and D259 (leiomyoma of uterus, unspecified). The surgical procedures were selected from the PMSI by selecting the specific codes of the French procedure classification (Classification Commune des Actes médicaux), as shown in table 1 .

\section{Historical data on the use of surgery for UF}

The PMSI data revealed two periods with respect to UF surgery (figure 1):

- Before the availability of UPA, from January 2007 to August 2013, when the annual number of UF surgeries was tending to rise;

- After the availability of UPA for preoperative use (August 2013 to 2015), when the annual number of UF surgeries tended to fall.

In contrast, the repartition of the age at surgery and the trends observed in the characteristics of the hospitals stays (severity index, type of surgery) were sustained over the whole period (online supplementary appendix).
The inflexion point in the number of surgeries observed at the time of launch of UPA was solely attributed to the efficacy of UPA, as:

- Both events (inflexion point and launch of UPA) were simultaneous;

- There was no other emerging healthcare technology or public health decision which could have impacted the management or the incidence of moderate to severe UF in France at this time.

Within this context, two scenarios were compared (figure 1):

- The counterfactual scenario, assuming non use of UPA: the trend observed before market release in France was extrapolated from August 2013 to 2019 by using linear regression and data recorded from January 2007 to August 2013 (+132 surgical procedures per year on average).

- The current scenario, with preoperative use of UPA: the trend in UF surgery after UPA market release in France was extrapolated to 2016 by using linear regression and data collected from August 2013 to the end of 2015 (-1132 surgical procedures per year

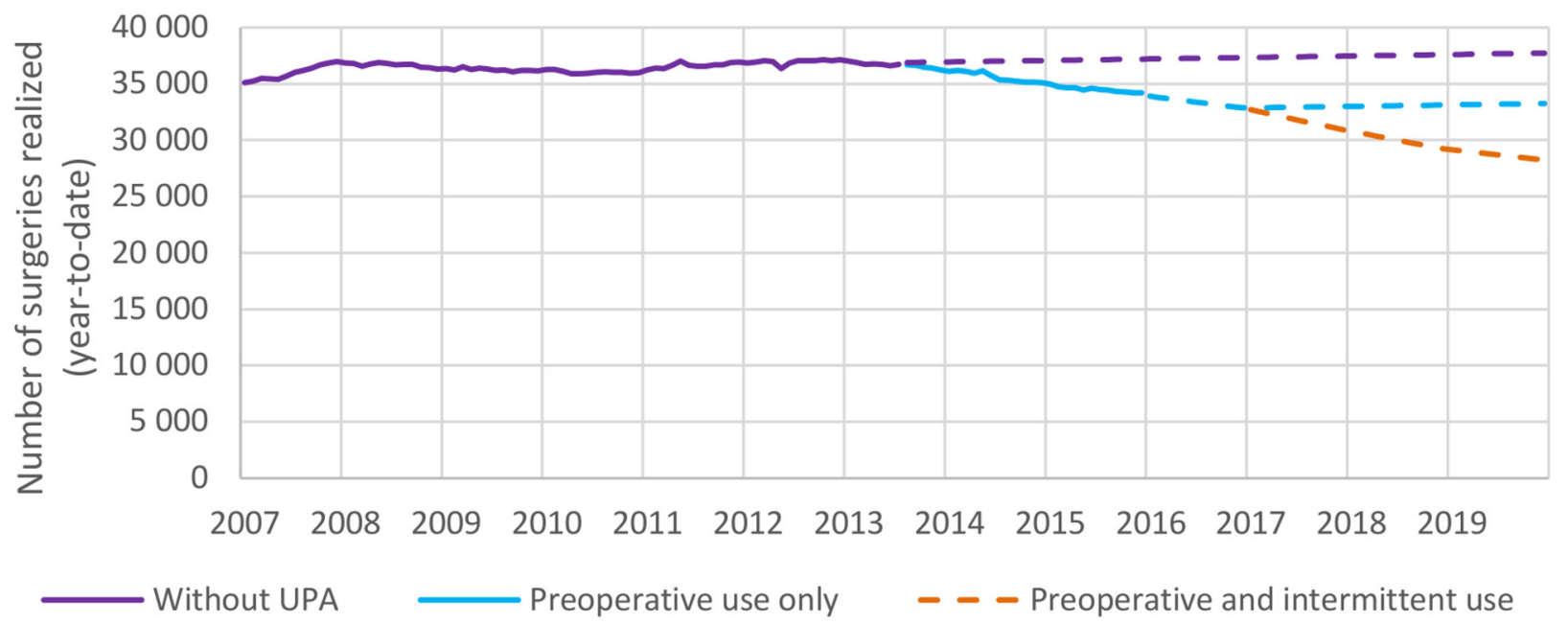

Continuous lines : historical frequencies / Dotted lines : extrapolated frequencies

Figure 1 Assessment of the impact of ulipristal acetate (UPA) on the number of surgical procedures for uterine fibroids in both scenarios. 
Table 2 Numbers of surgical procedures in the counterfactual and current scenarios

\begin{tabular}{llllllll}
\hline & $\mathbf{2 0 1 3}$ & $\mathbf{2 0 1 4}$ & $\mathbf{2 0 1 5}$ & $\mathbf{2 0 1 6}$ & $\mathbf{2 0 1 7}$ & $\mathbf{2 0 1 8}$ & $\mathbf{2 0 1 9}$ \\
\hline $\begin{array}{l}\text { Counterfactual scenario } \\
\text { without ulipristal acetate }\end{array}$ & $36940^{\star}$ & $37071^{\star}$ & $37203^{\star}$ & $37335^{\star}$ & $37466^{\star}$ & $37598^{\star}$ & $37729^{\star}$ \\
$\begin{array}{l}\text { Current scenario with } \\
\text { preoperative ulipristal acetate }\end{array}$ & 36216 & 35129 & 34224 & $32863^{\star}$ & $32995^{\star}$ & $33127^{\star}$ & $33258^{\star}$ \\
\hline
\end{tabular}

${ }^{\star}$ Extrapolated data

on average). Adopting a conservative approach, we postulated that market penetration of UPA as a preoperative treatment would reach a plateau at the end of 2016, and that trends in the number of surgical procedures, both with and without preoperative use of UPA, would be identical from that point onwards.

The annual numbers of surgeries performed in the two scenarios over the studied time horizon are shown in table 2. Further details about the linear extrapolation of the number of surgeries (initial data, regression coefficients and extrapolation results) are provided in online supplementary appendix.

The number of surgical procedures avoided through preoperative UPA treatment in the current scenario was measured as the difference in the number of surgical procedures performed in the current and counterfactual scenarios.

\section{Historical data on preoperative UPA therapy}

The numbers of UPA treatment units reimbursed ${ }^{18}$ in 2013, 2014, 2015 and 2016 were, respectively, 5328, 34 956, 54076 and 78762 , corresponding to 2220, 12 227, 18552 and 26954 treatment initiations $\mathrm{s}^{\mathrm{i}}$.

For subsequent years, it was assumed that market penetration would be maximal in this indication by the end of 2016 (stabilisation of the number of treatment initiations in the preoperative indication). The extrapolated numbers of treatment units were 80862 for each year from 2017 to 2019, corresponding to 26954 treatment initiations per year. In other words, we extrapolated that about $70 \%$ of scheduled surgeries between 2016 and 2019 would be preceded by UPA treatment.

\section{Exploratory scenario with the intermittent UPA indication}

The dose regimen considered for intermittent treatment in this analysis was that used in the PEARL IV trial, that is, four 3-month courses separated by a drug-free period until the start of the second menstrual period after the end of the previous course (approximately 2 months), with 3 months of follow-up after the fourth course (total study duration 21 months). The impact of intermittent indication on surgical procedures depends mainly on the age at which UPA treatment starts. When prescribed to a woman nearing the menopause, UPA could suppress

${ }^{\mathrm{i}}$ The estimation of the number of treatment initiations was based on the following hypotheses: (1) all treatment units were sold for the preoperative indication; (2) each patient took 3 treatment units; and (3) treatment initiations were smoothed over time. symptoms and result in postponement of surgery until beyond the menopause, when it would no longer be necessary for most women. Under these assumptions, UPA can be considered a relevant alternative to surgery.

Within this framework, the budget impact of the intermittent indication in the study population was estimated under the assumption that UPA would be prescribed first to women nearing the menopause ( $\geq 48$ years old) during the period 2017-2019, with the objective of avoiding surgery.

In this scenario, as the aim of intermittent treatment is to avoid surgery and, consequently, preoperative treatment, the benefits of preoperative treatment were estimated after taking into account surgical procedures avoided through the use of intermittent treatment. Thus, this exploratory analysis was modelled on the estimated number of surgical procedures in the counterfactual scenario.

Starting with the number of surgical procedures that would be done if UPA was not available, ${ }^{\text {ii }}$ we estimated that:

- About $31 \%$ of these procedures would have involved women aged $\geq 48$ years (analysis of the PMSI database showed that age at surgery was stable over time- figure 2);

- Respectively, 20\%, $40 \%$ and $60 \%$ of the surgeries warranted for women aged $\geq 48$ years in 2017, 2018 and 2019 would have been avoided thanks to intermittent UPA treatment, assuming market penetration similar to that observed for preoperative UPA during the first 3 years on the French market.

On this basis, the estimated numbers of women who would be prescribed intermittent treatment were 2348 in 2017, 4712 in 2018 and 7093 in 2019.

By smoothing those initiations uniformly over the year, the estimated numbers of treatment units reimbursed for intermittent treatment were 10566 in 2017, 36466 in 2018 and 64895 in 2019.

The annual number of surgical procedures would be reduced by the number of intermittent treatment initiations. At the end of intermittent UPA treatment, surgery was only supposed to proceed when the menopause did not occur during the treatment sequence. The probability that the menopause would occur during intermittent

\footnotetext{
${ }^{i i}$ Number of surgeries estimated in the counterfactual scenario, assuming the non use of UPA: 37466 in 2017, 37598 in 2018 and 37 729 in 2019.
} 


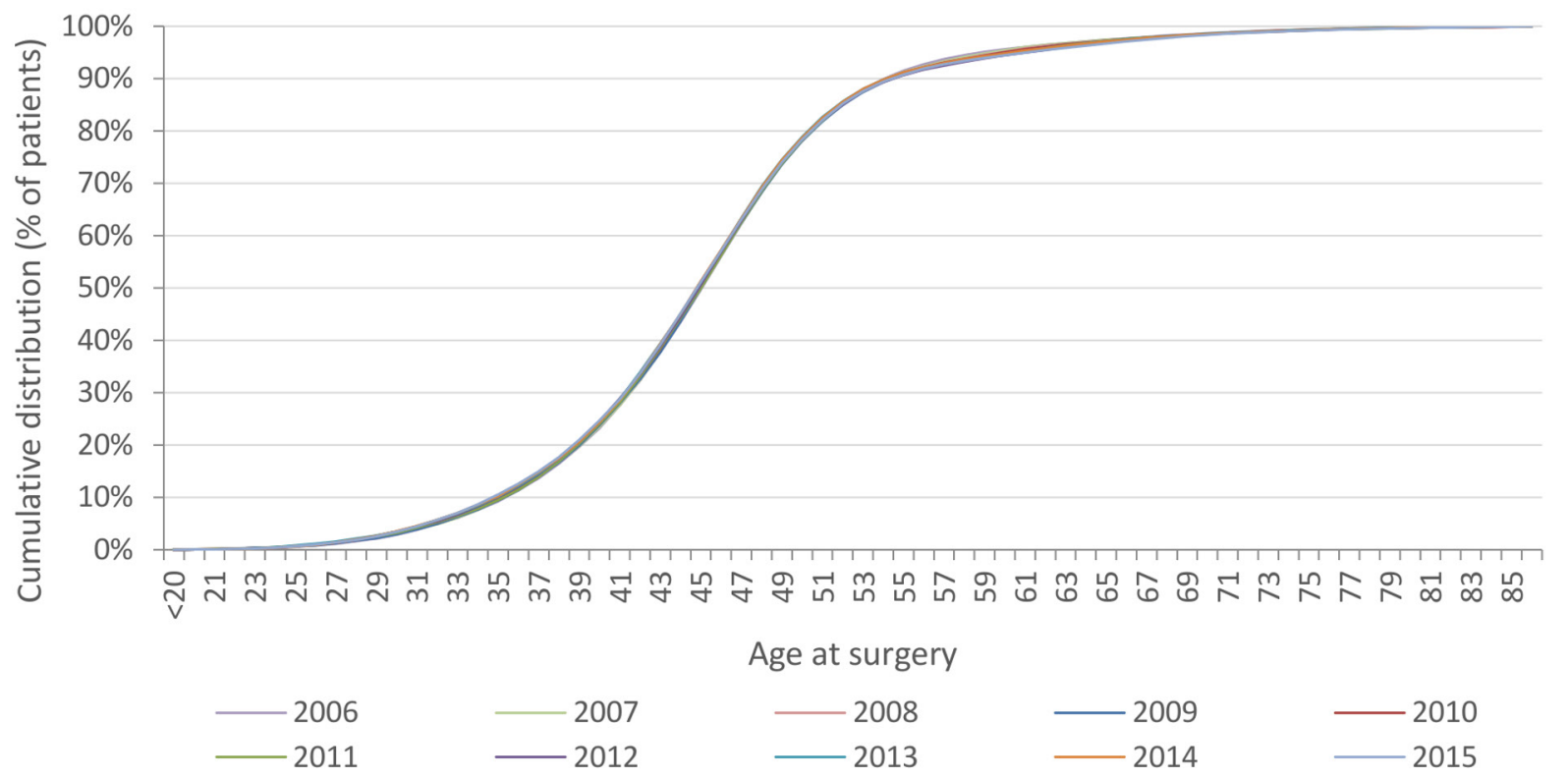

Figure 2 Age at surgery over time.

UPA treatment was estimated at 59\% among women aged $\geq 48$ years, based on information provided by the French National Authority for Health (Haute Autorité de Santé). ${ }^{19}$ Further details about the estimation of the probability of occurrence of menopause are provided in online supplementary appendix.

Taking into account intermittent treatment initiations, the resulting deferral of surgery and the cancellation of surgery in $59 \%$ of cases at the end of UPA treatment, we estimated that 35118,33129 and 31851 women, respectively, would be scheduled for UF surgery in 2017, 2018 and 2019. A graphical representation of the calculation is shown in figure 3 .

Finally, the subsequent impact of preoperative treatment was modelled in women eligible for surgery who did not start intermittent treatment during the study period ${ }^{\text {iii }}$. On the basis of the proportion of surgeries preceded by preoperative treatment and the proportion of surgeries avoided after preoperative treatment in the current scenario, we estimated that 25 265, 23576 and 21887 women would be prescribed preoperative treatment, resulting in 4191, 3911 and 3631 surgeries avoided in 2017, 2018 and 2019, respectively. The estimated numbers of treatment units reimbursed for this indication in the exploratory scenario were 76217 in 2017, 71150 in 2018 and 66083 in 2019.

By jointly considering the outcomes measured in both indications, the estimated number of surgical procedures in the exploratory scenario was 30927 in 2017, 29218 in 2018 and 28220 in 2019, with, respectively, 86 783, 107616 and 130978 UPA treatment units reimbursed over this period.

\footnotetext{
iii 35118 in 2017, 32886 in 2018, and 30636 in 2019.
}

The number of surgical procedures avoided by the use of UPA in both its indications was estimated in the exploratory scenario as the difference in the number of surgical procedures performed between the exploratory and counterfactual scenarios.

\section{Cost of surgical procedures}

For public hospitals, the costs of surgical procedures were calculated from 2015 public DRG tariffs. ${ }^{20}$ Private hospitals use the 2015 private DRG tariffs ${ }^{12}$ to which physician's fees were added, ${ }^{21}$ as they are not included in private DRG tariffs and are reimbursed on a fee-for-service basis. The estimated average cost of a surgical procedure for UF was $€ 2416$ ( $S D=1126$ ). Surgical procedures are fully reimbursed by the French national healthcare insurance system.

Detailed costs are shown in table 3 according to the type of surgery and route.

\section{Assessment of the budget impact}

The costs and benefits resulting each year from the current and exploratory scenarios were computed by taking the following steps:

- The costs avoided through the lesser use of surgery were estimated by multiplying the number of surgical procedures avoided in the relevant scenario by the total average cost of one surgical procedure;

- The amount reimbursed to patients by the French national healthcare insurance system for the use of UPA in the relevant scenario was estimated from the annual number of reimbursed treatment units in the relevant scenario, the public price of UPA and a $65 \%$ patient reimbursement rate. 


\begin{tabular}{|c|c|c|}
\hline $\begin{array}{l}\text { 35,118 surgeries scheduled in } \\
2017\end{array}$ & $\begin{array}{l}\text { 33,129 surgeries scheduled in } \\
2018\end{array}$ & $\begin{array}{l}\text { 31,851 surgeries scheduled in } \\
2019\end{array}$ \\
\hline$=$ & $=$ & $=$ \\
\hline $\begin{array}{l}\text { 37,466 surgeries done without } \\
\text { UPA in } 2017\end{array}$ & $\begin{array}{l}\text { 37,598 surgeries done without } \\
\text { UPA in } 2018\end{array}$ & $\begin{array}{l}37,729 \text { surgeries done without } \\
\text { UPA in } 2019\end{array}$ \\
\hline - & + & + \\
\hline $\begin{array}{l}2,348 \text { intermittent UPA treatment } \\
\text { initiations in } 2017\end{array}$ & $\begin{array}{l}243 \text { surgeries from } 2017 \text { deferred } \\
\text { to } 2018\end{array}$ & $\begin{array}{l}728 \text { surgeries from } 2017 \text { deferred } \\
\text { to } 2019\end{array}$ \\
\hline $2,348=37,466 * P_{\text {age group }} * 20 \%$ & $2,348 * 25 \%{ }^{[1]} *\left(1-P_{\text {menopause }}\right)$ & $2,348 * 75 \%{ }^{[1]} *\left(1-P_{\text {menopause }}\right)$ \\
\hline & - & + \\
\hline & $\begin{array}{l}\text { 4,712 intermittent UPA treatment } \\
\text { initiations in } 2018\end{array}$ & $\begin{array}{l}487 \text { surgeries from } 2017 \text { deferred } \\
\text { to } 2018\end{array}$ \\
\hline & $4,712=37,598 * P_{\text {age group }} * 40 \%$ & $4,712 * 25 \%{ }^{[1]} *\left(1-P_{\text {menopause }}\right)$ \\
\hline \multicolumn{3}{|c|}{$\boldsymbol{P}_{\text {age group }}$ : proportion of surgeries involving women $\geq 48$ years old $(31 \%)$} \\
\hline \multicolumn{2}{|c|}{$\begin{array}{l}\boldsymbol{P}_{\text {menopause }} \text { : probability of menopause occurrence during UPA treatment } \\
\text { among women } \geq 48 \text { years old }(59 \%)\end{array}$} & $\begin{array}{l}\text { 7,093 intermittent UPA treatment } \\
\text { initiations in } 2019\end{array}$ \\
\hline \multicolumn{2}{|c|}{$\begin{array}{l}\text { [1] : smoothing of UPA initiations over the year implies that 25\% (resp.75\%) } \\
\text { of surgeries in year Y are deferred to year } Y+1(\text { resp. } Y+2)\end{array}$} & $7,093=37,729 * P_{\text {age group }} * 60 \%$ \\
\hline
\end{tabular}

Figure 3 Calculation of the number of surgical procedures scheduled from 2017 to 2019 after taking into account the impact of intermittent ulipristal acetate (UPA) treatment.

\begin{tabular}{|c|c|c|c|c|c|c|c|}
\hline & 2013 & 2014 & 2015 & 2016 & 2017 & 2018 & 2019 \\
\hline \multicolumn{8}{|l|}{ Treatment costs resulting from the use of UPA } \\
\hline Number of reimbursed treatment units & 5328 & 34956 & 54076 & 78762 & 80862 & 80862 & 80862 \\
\hline $\begin{array}{l}\text { Amount reimbursed by the French national healthcare } \\
\text { insurance system (M€) }\end{array}$ & 0.5 & 3.2 & 5.0 & 7.3 & 7.5 & 7.5 & 7.5 \\
\hline \multicolumn{8}{|l|}{ Surgical procedures avoided by the use of UPA } \\
\hline Number of surgical procedures avoided & 724 & 1942 & 2979 & 4472 & 4471 & 4471 & 4471 \\
\hline Cost saving (M€) & 1.7 & 4.7 & 7.2 & 10.8 & 10.8 & 10.8 & 10.8 \\
\hline \multicolumn{8}{|l|}{ Budget impact of UPA } \\
\hline Annual (M€) & -1.3 & -1.5 & -2.2 & -3.5 & -3.3 & -3.3 & -3.3 \\
\hline Cumulative $(\mathrm{M} €)$ & -1.3 & -2.7 & -5.0 & -8.5 & -11.8 & -15.1 & -18.5 \\
\hline
\end{tabular}

UPA, ulipristal acetate. 
Finally, the budget impact in each scenario was calculated as the difference between the amount reimbursed for UPA by the French national healthcare insurance system in the relevant scenario and the costs avoided through the lesser use of surgery.

\section{Sensitivity analyses}

The sensitivity of the cumulative budget impact from 2013 to 2019 for each indication (preoperative and intermittent use) to the principal parameters was assessed in deterministic sensitivity analyses, in which each of the following parameters was varied individually:

- Number of surgical procedures: the bounds of the 95\% CIs for regression coefficients used to extrapolate the number of surgical procedures with and without preoperative UPA were used to derive potential worst-case and best-case scenarios for UPA. In the best-case scenario, the trend without UPA was maximised $(+177$ surgical procedures per year) and the trend with UPA was minimised $(-1207$ surgical procedures per year). In the worst-case scenario, the trend without UPA was minimised (+86 surgical procedures per year) and the trend with UPA was maximised ( -1057 surgical procedures per year);

- Budget impact from the societal perspective: each year, a study organised by the French Agency for Information on Hospital Care (Agence Technique de l'Information sur l'Hospitalisation) estimates the costs associated with hospital stays from a societal perspective, using an analytical accounting system in a sample of French hospitals. ${ }^{22}$ Using data from this study, we estimated that the total average cost of a surgical procedure was $€ 2810$. In keeping with the societal perspective, the hospital per diem charges, which are supported by the patient, were added to the total cost of the surgical procedure. Those charges depend on the length of the hospital stay and were estimated at $€ 72$. In this analysis, total UPA treatment costs were considered, rather than the portion reimbursed by CNAM;

- Indirect costs associated with sick leave: one particularity of the French national healthcare system is partial compensation for sick leave. The national database (DAMIR) ${ }^{23}$ gathering all expenditures of the French national healthcare insurance system allowed us to estimate the average daily compensation for sick leave at $€ 31$. By taking into account an average 30-day period of sick leave after UF surgery ${ }^{24}$ and an employment rate of $92 \%$ among women with UF, (Observational epidemiological study realized by Kantar Health for Gedeon Richter, unpublished data) the average cost of sick leave after UF surgery was estimated at $€ 856$;

- Duration of exposure during intermittent treatment: based on the PEARL II results showing a maintenance of the effect of UPA on UF size and no return to initial symptoms severity scores 6 months after treatment, and on PREMYA ${ }^{25}$ results confirming the satisfaction of both patients and healthcare professionals at least 6 months after treatment cessation, the off-treatment periods and the follow-up period were both extended to 6 months. The total duration of UPA exposure during intermittent treatment was therefore expanded to 36 months. This assumption has an impact on the probability of menopause occurring during intermittent treatment and the age at which intermittent treatment can be prescribed with the objective of avoiding surgery. Accordingly, intermittent treatment was supposed to be prescribed in women aged $\geq 47$ years in this analysis.

\section{RESULTS}

\section{Current scenario}

From 2013 to 2015, 94360 UPA treatment units were reimbursed by the French national healthcare insurance system for the preoperative indication, costing $€ 8.7$ million. Over the same period, use of UPA was associated with 5645 fewer surgeries. The resulting cost saving was estimated at $€ 13.6$ million.

From 2016 to 2019, the number of UPA treatment units reimbursed by the French national healthcare insurance system for the preoperative indication was extrapolated to 321348 units, for a cost of $€ 29.7$ million. Over the same period, extrapolation suggested 17885 fewer surgeries, saving $€ 43.2$ million.

Finally, the estimated cumulative budget impact of preoperative UPA from 2013 to 2019 was $€-18.5$ million. Detailed annual results are shown in table 4 . The number of surgeries performed in each scenario is shown on a larger timeframe in figure 1.

\section{Exploratory scenario}

From 2013 to 2016, the exploratory and current scenarios produced the same outcomes, with an estimated

Table 4 Average cost of surgical procedures according to the type of surgery and route in 2015

\begin{tabular}{llll}
\hline Access route & Hysterectomy & Myomectomy & Embolisation \\
\hline Vaginal & $2975 €(N=4966)$ & & \\
Laparoscopy & $3040 €(N=5476)$ & $2434 €(\mathrm{~N}=1706)$ & \\
Laparotomy & $3283 €(\mathrm{~N}=7566)$ & $1154 €(\mathrm{~N}=10333)$ & $1786 €(\mathrm{~N}=654)$ \\
Hysteroscopy & & & \\
Intra-arterial & & & $1 \mathrm{~N}=3523)$ \\
\hline
\end{tabular}


Table 5 Budget impact of preoperative and intermittent ulipristal acetate (UPA) in the exploratory scenario

\begin{tabular}{|c|c|c|c|c|c|c|c|}
\hline & 2013 & 2014 & 2015 & 2016 & 2017 & 2018 & 2019 \\
\hline \multicolumn{8}{|l|}{ Cost of UPA } \\
\hline Number of reimbursed treatment units & 5328 & 34956 & 54076 & 78762 & 86783 & 107616 & 130978 \\
\hline $\begin{array}{l}\text { Amount reimbursed by the French national } \\
\text { healthcare insurance system }(M €)\end{array}$ & 0.5 & 3.2 & 5.0 & 7.3 & 8.0 & 9.9 & 12.1 \\
\hline \multicolumn{8}{|l|}{ Surgical procedures avoided by the use of UPA } \\
\hline Number of surgical procedures avoided & 724 & 1942 & 2979 & 4472 & 6539 & 8380 & 9509 \\
\hline Costs avoided (M€) & 1.7 & 4.7 & 7.2 & 10.8 & 15.8 & 20.2 & 23.0 \\
\hline \multicolumn{8}{|l|}{ Budget impact of UPA } \\
\hline Annual (M€) & -1.3 & -1.5 & -2.2 & -3.5 & -7.8 & -10.3 & -10.9 \\
\hline Cumulative (M€) & -1.3 & -2.7 & -5.0 & -8.5 & -16.3 & -26.6 & -37.4 \\
\hline
\end{tabular}

cumulative UPA budget impact of $-€ 8.5$ million over the period.

From 2017 to 2019, by comparison with the current scenario, the arrival of intermittent UPA treatment in the exploratory scenario was associated with an increase in the number of reimbursed treatment units and in the number of surgical procedures avoided. With 325377 treatment units reimbursed from 2017 to 2019 in the exploratory scenario, we estimate that treatment costs in the study population would increase by $34.1 \%$ after the arrival of intermittent UPA, cumulating at €30.1 million over the period. On the other hand, we estimated that the number of surgical procedures avoided from 2017 to 2019 would increase by $82.1 \%$ after the arrival of intermittent UPA, resulting in a cost saving of $€ 59$ million over the period. Overall, the cumulative budget impact of UPA from 2017 to 2019 in this scenario was estimated at $€-28.9$ million.

Finally, the cumulative budget impact of UPA in both indications from 2013 to 2019 was estimated at $€-37.4$ million. Detailed annual results are shown in table 5 . The number of surgeries performed in each scenario is shown on a larger timeframe in figure 1.

Over the studied time horizon, the economic benefit of UPA is due jointly to the increasing market penetration of intermittent treatment and to the deferral of surgery. Over the long term, when prescriptions for intermittent treatment have stabilised, the economic benefits associated with the intermittent indication will be entirely driven by the number of surgeries that are cancelled because of menopause occurrence. However, with an average $59 \%$ probability of menopause occurrence during intermittent treatment, UPA is still expected to save costs for the French national healthcare insurance system over the long term, when prescribed to women aged $\geq 48$ years .

\section{Sensitivity analyses}

The results were mostly sensitive to the extrapolation of the number of surgical procedures, the perspective, and surgical costs (table 6). However, the use of UPA was always associated with considerable savings for the French national healthcare insurance system in both scenarios.

\section{DISCUSSION}

This study based on observational retrospective data shows that the use of UPA in its first, preoperative indication resulted in substantial cost savings ( $€ 5$ million) for the French national healthcare insurance system from 2013 to 2015. The corresponding savings extrapolated from 2016 to 2019 were $€ 13.5$ million. The incremental benefits associated with the intermittent treatment indication were estimated at $€ 19$ million from 2017 to 2019. However, the economic benefits of intermittent treatment

Table 6 Sensitivity of the cumulative budget impact (M€) of UPA to the principal parameters from 2013 to 2019 , in its two indications

\begin{tabular}{lll}
\hline Scenario & $\begin{array}{l}\text { Current scenario: } \\
\text { Preoperative use only }\end{array}$ & $\begin{array}{l}\text { Exploratory scenario: Both } \\
\text { indications available }\end{array}$ \\
\hline Reference analysis & -18.5 & -37.4 \\
Worst-case extrapolation of the number of surgeries & -2.7 & -22.5 \\
Best-case extrapolation of the number of surgeries & -34.3 & -52.4 \\
Budgetary impact from societal perspective & -8.8 & -28.7 \\
Indirect costs associated with sick leave & -38.6 & -67.0 \\
36-month intermittent treatment period & -18.5 & -48.5 \\
\hline
\end{tabular}

UPA, ulipristal acetate. 
are likely to decrease over time, due to stabilisation of prescriptions and to a lesser impact of temporary deferral of surgery. Even in the long term, intermittent treatment is expected to save costs for the French national healthcare insurance system in the study population by offering a curative medical option for perimenopausal women.

There are no comparable pharmacoeconomic evaluations of UPA in the literature. An Italian study ${ }^{26}$ compared intermittent use to preoperative use, estimating the incremental cost-effectiveness ratio between the two strategies and the budget impact of intermittent treatment. The authors concluded that compared with former preoperative use, intermittent UPA therapy had a favourable pharmacoeconomic profile and was cost saving for the national healthcare system. Our results are consistent with these findings, as we found that intermittent treatment was associated with more substantial benefits than preoperative treatment in comparable marketing conditions.

The budget impact of the preoperative indication reported here is based on real-world data recorded in France at the national level and on conservative economic assumptions. During the observation period, no other explanation was found for the inflexion point noted when UPA was first marketed, especially as both events (inflexion point and launch of UPA) were simultaneous and proportional (the estimated proportion of surgeries avoided per initiation to preoperative treatment was stable over time, that is, $15.8 \%$ in $2014,16.1 \%$ in 2015 and $16.6 \%$ in 2016). Extrapolation of the economic benefit of this first indication to future years was less factual, but we adopted a conservative approach by assuming that prescriptions would reach a plateau.

More assumptions were used for the exploratory scenario, and the estimates are, therefore, less robust. However, the economic benefits associated with surgery avoidance through the use of intermittent treatment depended on the probability of menopause occurring during the UPA treatment sequence. The results of the PEARL II study, confirmed by real-world data in the PREMYA study, ${ }^{25}$ suggest that this approach is conservative, as efficacy and satisfaction persisted at least during a 6-month follow-up period.

In routine practice, the precise level of cost savings will depend on effective UPA usage by physicians, and on the ability to adjust the dose regimen to the individual patient. Also, some patients could be treated for longer than expected, depending on symptoms occurrence and the wish of the patient to avoid or postpone surgery.

The present evaluation was limited to a portion of the therapeutic area targeted by intermittent treatment. As UPA can control UF symptoms for long periods, intermittent treatment is likely to be increasingly prescribed to women with less severe symptoms and to younger patients with childbearing potential.

Too little real-world information is available to address the use of intermittent UPA in routine practice, whereas the impact of preoperative treatment on the use of surgery has been robustly quantified. Analyses of intermittent
UPA treatment based on French medical-administrative databases will help answer this question.

Contributors HF assures that all authors included in the paper fulfil the criteria of authorship, and that there are no other persons who satisfied the criteria of authorship, but are not listed. All authors have seen and approved the final version of the manuscript being submitted. Each author had the following role: design of the work: HF, OJ, VV, ML, AL, MT; analysis of data and modeling: ML, AL, MT; interpretation of results: HF, OJ, VV, ML, AL, MT; writing of the paper and proofreading: HF, OJ, VV, ML, AL, MT. The submitted work was integrally achieved by the authors, organised as an independent committee gathering experts in uterine fibroids (HF, OJ, VV) and technical specialists in health technology assessment (ML, AL, MT).

Competing interests Financial support for all authors from GEDEON-RICHTER for the submitted work; financial relationship between Matthieu LEHMANN and GEDEON-RICHTER (employee); no other relationships or activities that could appear to have influenced the submitted work.

Provenance and peer review Not commissioned; externally peer reviewed.

Data sharing statement Budget Impact Model, developed under Microsoft Excel, available with open access from the Corresponding Author at herve.fernandez@ aphp.fr

Open Access This is an Open Access article distributed in accordance with the Creative Commons Attribution Non Commercial (CC BY-NC 4.0) license, which permits others to distribute, remix, adapt, build upon this work non-commercially, and license their derivative works on different terms, provided the original work is properly cited and the use is non-commercial. See: http://creativecommons.org/ licenses/by-nc/4.0/

(C) Article author(s) (or their employer(s) unless otherwise stated in the text of the article) 2017. All rights reserved. No commercial use is permitted unless otherwise expressly granted.

\section{REFERENCES}

1. Khan AT, Shehmar M, Gupta JK. Uterine fibroids: current perspectives. Int J Womens Health 2014;6:95-114.

2. Brito LG, Panobianco MS, Sabino-de-Freitas MM, et al. Uterine leiomyoma: understanding the impact of symptoms on womens' lives. Reprod Health 2014;11:10.

3. Zimmermann A, Bernuit D, Gerlinger C, et al. Prevalence, symptoms and management of uterine fibroids: an international internet-based survey of 21,746 women. BMC Womens Health 2012;12:6.

4. Fernandez H, Chabbert Buffet N, Allouche S. [Prevalence of uterine fibroids in France and impact on quality of life: results of a survey among 2500 women between 30-55 years]. J Gynecol Obstet Biol Reprod 2014;43:721-7.

5. Wallach EE, Vlahos NF. Uterine myomas: an overview of development, clinical features, and management. Obstet Gynecol 2004;104:393-406.

6. Maruo T, Ohara N, Yoshida S, et al. Lessons learned from the preclinical drug discovery of asoprisnil and ulipristal for nonsurgical treatment of uterine leiomyomas. Expert Opin Drug Discov 2011;6:897-911.

7. Tal R, Segars JH. The role of angiogenic factors in fibroid pathogenesis: potential implications for future therapy. Hum Reprod Update 2014;20:194-216.

8. Donnez J, Tatarchuk TF, Bouchard P, et al.Ulipristal acetate versus placebo for fibroid treatment before surgery. $N$ Engl $\mathrm{J}$ Med 2012;366:409-20.

9. Donnez J, Tomaszewski J, Vázquez F, et al. Ulipristal acetate versus Leuprolide Acetate for uterine fibroids. $N$ Engl J Med Overseas Ed 2012;366:421-32.

10. Donnez J, Donnez O, Matule D, et al. Long-term medical management of uterine fibroids with ulipristal acetate. Fertil Steril 2016;105:165-73.

11 Donnez J, Vázquez F, Tomaszewski J, et al. PEARL III and PEARL III Extension Study Group. Long-term treatment of uterine fibroids with ulipristal acetate. Fertil Steril 2014;101:1565-73.

12. European Medicine Agency http://www.ema.europa.eu/docs/en GB/document library/EPAR - Public assessment report/human/ 002041/WC500124088.pdf 
13. Arrêté du 22 juillet 2013 modifiant la liste des spécialités pharmaceutiques remboursables aux assurés sociaux. https://www.legifrance.gouv.fr/affichTexte.do;jsessionid= AB89B8DE6FBB9762448BA5540B4EEE7C.tpdila14v_1?cidTexte $=$ JORFTEXT000027748918\&dateTexte=\&oldAction=rechJO\&cate gorieLien=id\&idJO=JORFCONT000027748776

14. Commission De La Transparence http://www.has-sante.fr/portail/ upload/docs/application/pdf/2012-09/esmya_18072012_avis_ ct12237.pdf

15. Donnez J, Tomaszewski J, Vázquez F, et al. PEARL II Study Group. Ulipristal acetate versus leuprolide acetate for uterine fibroids. $N$ Engl J Med 2012;366:421-32.

16. European Medicine Agency http://www.ema.europa.eu/docs/en_GB/ document_library/EPAR_-_Assessment_Report_-_Variation/human/ 002041/WC500189366.pdf

17. Sullivan SD, Mauskopf JA, Augustovski F, et al. Budget impact analysis-principles of good practice: report of the ISPOR 2012 Budget Impact analysis good practice II Task Force. Value Health 2014;17:5-14.

18. Data extracted from the exhaustive drug reimbursement claims (Medic'AM) provided by the French national healthcare insurance system. http://www.ameli.fr/l-assurance-maladie/statistiques-etpublications/donnees-statistiques/medicament/medic-am $/$ medicam-mensuel-2016.php

19. Rapport Traitement hormonal substitutif de la ménopause. Anaes (HAS) / Afssaps, argumentaire mai 2004.

20. $M C O$ and HAD rates. http://www.atih.sante.fr/tarifs-mco-et-had

21. CCAM Online. http://www.ameli.fr/accueil-de-la-ccam/index.php

22. National Cost Studies - Presentation and recruitment. http://www. atih.sante.fr/information-sur-les-couts/etudes-nationales-de-coutspresentation-et-recrutement

23. Open Damir: comprehensive database on interregional health insurance expenditure. http://open-data-assurance-maladie.ameli.fr/ depenses/index.php

24. Hystérectomie. http://www.ameli.fr/fileadmin/user_upload/ documents/memo AT hysterectomie BD.pdf

25. Fernandez H, Schmidt T, Powell M, et al. Real world data of 1473 patients treated with ulipristal acetate for uterine fibroids: premya study results. Eur J Obstet Gynecol Reprod Biol 2017;208:91-6.

26. Maratea D. Repeated-intermittent use of ulipristal acetate for the management of uterine fibroids: an italian pharmacoeconomic evaluation. Minerva Ginecol 2016;68:15-20. 